\title{
Symmetric giant xanthogranulomas in Erdheim-Chester disease
}

\author{
Takafumi Taguchi $\cdot$ Shigetoshi Sano • \\ Yasumasa Iwasaki • Yoshio Terada
}

Received: 11 February 2009 / Accepted: 24 February 2009/Published online: 19 March 2009

(C) Springer-Verlag 2009

\begin{abstract}
A 33-year-old woman admitted to our hospital presenting with polyarthralgia, diabetes insipidus and xanthogranulomas in a subcutaneous precordial region and long bones was histologically diagnosed with Erdheim-Chester disease (ECD) [1]. Despite 5 years of treatment with prednisolone, cyclophosphamide and imatinib mesylate after the original diagnosis, subcutaneous xanthogranulomas again developed. ${ }^{18}$ F-FDG PET/CT revealed symmetric xanthogranulomas in the retroauricular regions, axillae, in tissue surrounding the psoas major muscle and in the long bones (arrows). These were histologically and immunologically confirmed as being consistent with ECD. Symmetric lesions of the long bones have generally been observed in ECD patients [2, 3]; however, our PET/CT images clearly showed symmetric cutaneous xanthogranulomas. Such symmetric anatomical changes, especially at tendon attachments or in connective tissue, may be an important clue to clarifying the aetiology of ECD.
\end{abstract}

T. Taguchi $(\bowtie) \cdot$ S. Sano $\cdot$ Y. Iwasaki $\cdot$ Y. Terada Kochi Medical School, Kochi University,

Kohasu Oko-cho,

Nankoku 783-8505, Japan

e-mail: tagu@muse.ocn.ne.jp
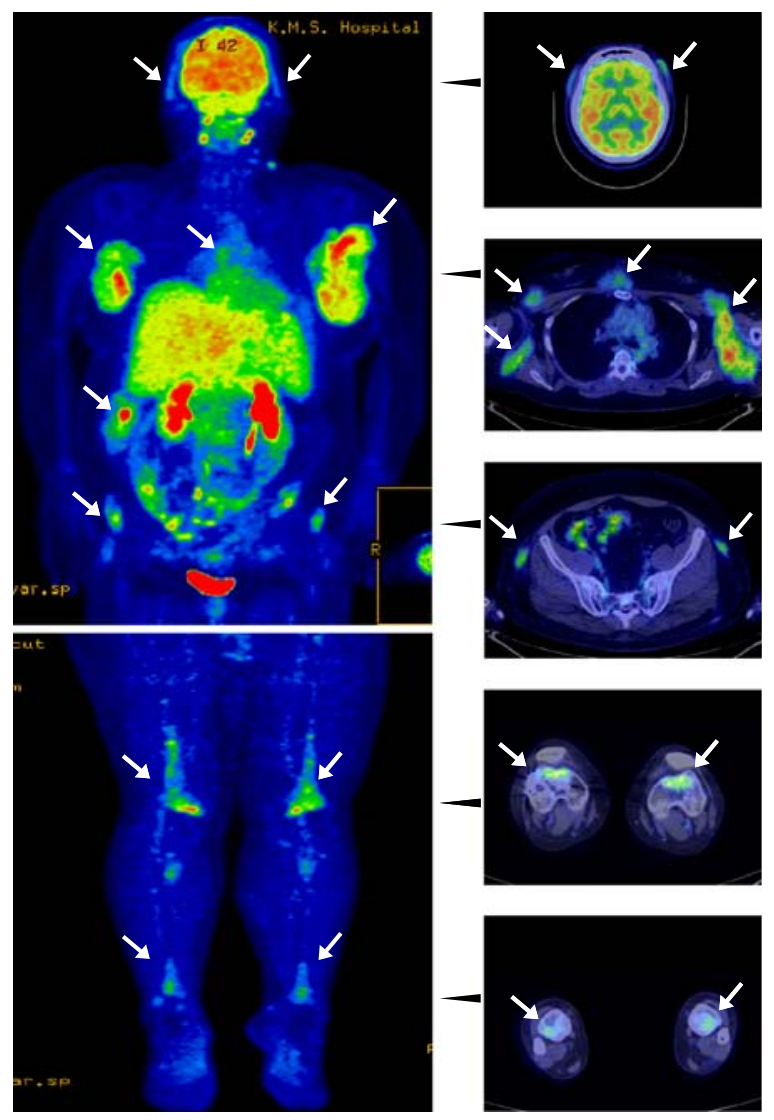

\section{References}

1. Taguchi T, Iwasaki Y, Asaba K, Yoshida T, Takao T, Ikeno F, et al. Erdheim-Chester disease: report of a case with PCR-based analysis of the expression of osteopontin and survivin in xanthogranulomas following glucocorticoid treatment. Endocr J 2008;55:217-23. doi: 10.1507/endocrj.K07E-044.

2. Canbaz F, Dabak N, Baris S, Selcuk MB. Erdheim-Chester disease: $99 \mathrm{mTc}-\mathrm{MDP}$ bone scan provides the diagnosis. Eur J Nucl Med Mol Imaging 2005;32:998. doi: 10.1007/s00259-005-1817-9.

3. Namwongprom S, Nunez R, Kim EE, Macapinlac HA. Tc-99m MDP bone scintigraphy and positron emission tomography/computed tomography (PET/CT) imaging in Erdheim-Chester disease. Clin Nucl Med 2007;32:35-8. doi: 10.1097/01.rlu.0000249758.49841.fa. 